\title{
The Influence and Countermeasures of Citizen Participation in Crisis Management in the Internet Age
}

\author{
$\mathrm{Ke} \mathrm{YAO}^{*}$ \\ No.5 Guang Ming Road, Xi'an, Shanxi Province, University of Defense Technology, P.R. China
}

\begin{abstract}
Citizen participation mainly focuses on citizens 'participation in social policies and supervision of public power. Citizen participation in the Internet age has shown some new characteristics in terms of scope of participation, willingness to participate, and means of participation, and it has a profound impact on the process, environment and standards of social crisis management. Public administration departments are urgently required to respond appropriately in terms of regulations, expression channels, etc. Keywords: Citizen participation, Crisis management, Cyber age
\end{abstract}

\section{The definition and characteristics of citizen participation in the cyber age}

Crisis is usually a combination of a variety of unfavorable situations, such as serious threats or challenges to the core values of policy makers, insufficient information, highly uncertain developments and the need for rapid decision-making [2]. Crisis management, as an organized, planned and continuous dynamic management process, is a series of control actions taken by the government or organization at different stages of crisis development in response to potential or current crises in order to effectively prevent, deal with and eliminate crisis [3]. Participation is one of the core concepts of political theory. Citizen participation originally emphasized the confirmation and maintenance of the national political system. With the rise of governance theory and public management theory, the meaning of citizen participation has gradually expanded and deepened, and it has begun to focus on social policy participation and public power supervision [4]. Based on the above understanding, citizen participation in the Internet era mainly refers to the process in which citizens participate in the management of public affairs by means of information under the network background and exert influence on the formation of public policies.

Citizen participation in the Internet age has some typical characteristics. Firstly, the breadth and depth of citizen participation has been expanded. The characteristics of open network, virtual, instant, and sharing have greatly expanded the breadth and depth of citizen participation in public affairs. Citizens who are willing can participate in public affairs at anytime, anywhere, intentionally or unintentionally. The distinctive and segmented participation model has been hit and challenged. But it is worth noting that online hotspots

* Corresponding author: $463872349 @$ qq.com 
change frequently, and the degree of citizen participation is constrained by the continuity of the issues and the intensity of the overlay. Secondly, the ability and willingness of citizens to participate has been significantly enhanced. With the widespread use of the Internet, the "information gap" between public power managers and ordinary people in the incident was quickly filled. Ordinary people can grasp information at the same time or even earlier, so as to intervene managers' decisions by the advantage of information acquisition. On the one hand, it has led to a marked increase in the willingness of citizens to participate. On the other hand, it also puts forward higher requirements on the ability of ordinary citizens to discern and to deal with public affairs. Thirdly, the methods and means of citizen participation are more diverse. Ordinary citizens in the Internet age can express their opinions and influence decision-making through network comments, and can also organize network collective activities and network signatures to conduct network mobilization to form consensus and raise issues. In addition, the rapid development of information technology has made it possible to use big data and other means to analyze and collect citizens 'propensity for certain issues and related activity information, which means that the problem of citizens' passive participation has become increasingly prominent.

\section{Analysis of the impact of citizen participation on crisis management in the Cyber age}

\subsection{Accelerate the evolution of the crisis management process}

Citizen participation in the cyber age has exposed the crisis management process to more external controls. The typical crisis management process generally includes prevention, emergency, recovery and other stages. The operation of each stage is in a relatively closed environment. There is a clear sequence between the stages. People are also used to mobilizing resources in the process of stylization, coordinate information and solve problems. In the Internet age, all aspects of crisis management are in a more transparent and open state, and are always subject to public supervision and feedback. The public has turned from a service object to a participant and the evolution of crisis management has changed from the previous single thread to multi thread. For example, the new coronavirus crisis management that broke out at the beginning of the year, under the deployment of a game of chess across the country, has a distinction between prevention, emergency, and recovery in different regions. At the same time, there has also been a situation where community prevention, medical department treatment, and public service system gradually resumes production go hand in hand.

\subsection{The crisis management environment is becoming more and more complex}

Crisis management in the Internet age faces a more complex management environment. The first is that management entities are more diversified. The main body of public crisis management in the cyber age is showing a diversified trend. In the traditional sense, crisis management and control mainly rely on administrative and organizational forces. With the development of mobile terminals and social media platforms in the Internet era, individuals and temporary groups are more widely involved in crisis prevention, evaluation, and recovery. The process of crisis management is facing scientific and refined challenges. Secondly, the crisis management environment is more complex and changeable. The network can not only contain the crisis, but also create it. The Internet has greatly promoted the communication and exchange between people, essentially changed the way of communication between organizations, society and individuals, and enhanced people's ability to manage and control crises. But at the same time, the Internet has quietly lowered the aggregation standards of 
social relations and speech circles, accelerated the evolution of issues, and made rational information in crisis management interfered by emotional information, attitude information, and moral judgment, and related behaviors are difficult to define, which may cause the crisis to be amplified and superimposed, and weaken people's ability to manage the crisis.

\subsection{Crisis management standards are more diverse}

Crisis management aims to solve the crisis and reduce disasters, and management effectiveness is an important criterion for judging its success. However, with the development of the Internet and the popularization of online citizen participation, moral factors are becoming an important consideration in judging crisis management activities. On the one hand, the network has the powerful function of aggregating and releasing public opinion. The process of releasing public opinion is not only a process of forming public opinion, but also a process of generating social judgment. This process inevitably leads to the emergence of moral judgment. On the other hand, to more followers, they can also feedback to the crisis manager more quickly and force them to respond to it, resulting in moral judgment becoming another important indicator of crisis management activities.

\section{Suggestions on improving citizens' participation in crisis management in the cyber age}

\subsection{Actively adapt to environmental changes}

Firstly, Crisis managers in the Internet age must actively update traditional thinking, adapt to the new public opinion environment, and use new media to respond to the crisis with the assistance of ordinary people. Secondly, transition from the focus on information and flow to the focus on "people" and "relationships" can't be ignored. We can reduce the social resistance of emergency management by guiding public opinion and responding to concerns. At last, it is necessary to use the more credible platform to release information in a timely manner to strengthen the guidance of public opinion, pay attention to using the power of "action", and take the initiative to increase the right to speak and influence.

\subsection{Strengthen the construction of expression channels}

Although China's civic participation has developed in the Internet era, it is still in a relatively autonomous and disorderly stage, and has not yet formed a joint force to become the mainstream. In crisis management, it is necessary to strengthen the construction of channels for citizen participation, such as publicizing emergency management plans on the Internet, collecting improved suggestions, organizing management education activities, etc. Additionally, we can inform citizens about relevant content in advance, increase the transparency of policy decisions and encourage Citizens of all classes, ages, and genders to participate in it and enhance the fairness of decision-making.

\subsection{Improve the construction of laws and regulations}

At present, the efficient mobilization of the whole society to actively participate in crisis management activities is not only a social development requirement in the information age, but also a realistic choice for us to respond to crises. Facing the new situation of citizen participation, we should gradually improve the construction of laws and regulations on 
citizen participation and strengthen the protection of online citizen participation and reward and punishment of relevant responsibilities by standardizing the procedures of citizen participation, defining powers and obligations, and strengthening information release management.

\section{References}

1. G Plancque, D You, E Blanchard, V Mertens, C Lamouroux. Role of chemistry in the phenomena occurring in nuclear power plants circuits, in Proceedings of the International Congress on Advances in Nuclear power Plants, ICAPP, 2-5 Nice, France (2011)

2. W Wang. Citizen Participation. Renmin University of China Press, 2009.

3. X Zhang, J L Wang, 25 Years of Chinese Internet. The official account of People's Network, (2019)

4. L Xue, Q Zhang, K H Zhong. Challenges facing China during the crisis management transition period. Beijing: Tsinghua University Press, 41-45, (2003)

5. C F Zhang. Public Crisis Management: Fully Integrated Model and China's Strategic Choice. China Administration, 77, (2003)

6. L Ping. Moral Analysis of Citizens' Daily Behavior. Beijing: People's Publishing House, 111 (2004) 